\title{
Por um Ensino relevante da Química: Que papel para o Trabalho Experimental?
}

«Temos talvez o instrumento adequado mas não o estamos usando adequadamente»

A. Johnstone

\section{Posição do problema}

Uma das maneiras pela qual a investigação em Educação em Química pode ser útil aos professores é ajudá-los a reflectir sobre as suas próprias práticas. Este breve estudo insere-se nessa lógica e o seu objectivo é contribuir para um maior escrutínio no que respeita ao uso do trabalho experimental (TE) no ensino da Química (14/17 anos). Na verdade, sendo o TE uma actividade em relação à qual os professores investem normalmente grandes expectativas pedagógicas e que consome grande parte do tempo e dos recursos dedicados ao ensino, nem sempre é claro se um dado tipo de TE é o mais adequado tendo em vista um determinado objectivo de ensino $[1,2]$. Tal falta de convergência tem provavelmente a ver com a própria falta de consenso (entre investigadores e/ou professores) sobre os quais os objectivos do TE, apesar de extensa investigação sobre este tema $[3,4]$. De líquido fica a certeza de que os objectivos do TE são múltiplos e função do nível de ensino a que esse trabalho se dirige.

Da falta de consenso sobre quais os objectivos do TE resulta ser pouco aconselhável propor aos professores modelos normativos de TE, situação no entanto frequentemente encontrada na literatura da especialidade. Por essa razão, desenvolve-se neste estudo uma metodologia alternativa de análise do uso de TE que, embora menos formal, pode eventualmente ser mais útil aos professores de Química. Tal metodologia consiste, no essencial, em sistematizar numa matriz de decisões atributos e vantagens relativas à aplicação de formatos correntes de TE de modo a dar aos professores a possibilidade de escolhas individuais mais informadas em função dos seus próprios objectivos e condições concretas de trabalho, i.e., contextualizar as suas decisões. $\mathrm{O}$ problema deixa pois de ser "qual o formato de TE que se deve seguir" para ser "qual o formato de TE mais aconselhável para os meus alunos".

$\mathrm{Na}$ discussão dos diferentes formatos adoptou-se um modelo de ensino/aprendizagem de raiz construtivista [5] de modo a realçar o carácter problemático do conhecimento. De notar que tal perspectiva não coincide com pressupostos psicopedagógicos e epistemológicos frequentes e que no caso do TE sã̃o sede de alguma confusão sobre o sentido que se lhe deve atribuir, nomeadamente: (i) Activismo, i.e., pelo facto dos alunos estarem fisicamente em actividade eles aprendem necessariamente melhor. Com efeito, “... é uma ilusão acreditar que a acção ainda que levada a cabo pelos alunos, contém em si mesma o poder de produzir conhecimento"' [6]. Há pois que distinguir entre o su- jeito activo na construção do seu conhecimento e uma mera expressão do operacionalismo pedagógico, (ii) Cientismo, i.e., pretensa correspondência do TE, nomeadamente no caso do chamado método de descoberta (pura), à fase experimental da investigação científica no pressuposto que tal conduz a uma superior formação dos conceitos pelos alunos. Uma tal perspectiva, frequentemente assumida pelos próprios alunos [7], tem subjacente o empirismo lógico e é naturalmente falaciosa já que a descoberta científica exige sólidos conhecimentos prévios. Acresce que se corre o risco de promover nos alunos uma visão deturpada da Química, dado que parece difícil de conciliar a natureza problemática do conhecimento com o uso do TE conduzindo o mais das vezes a uma só solução, a solução do professor [8]. A este respeito pode ser útil a distinção feita entre "descobrir que" e "descobrir porquê"' [9]. Por exemplo, descobrir que a temperatura influencia a velocidade das reacções químicas é bem menos problemático para os alunos do que descobrir porque é que tal efeito tem lugar.

\section{Tipologia do trabalho experimental}

A nível do $3 .^{\circ}$ ciclo do Ensino Básico e Ensino Secundário, o TE em Portugal envolve no essencial três formatos: Demonstrações (D), Verificações (V) e Explorações (E). Os dois primeiros são os mais típicos (mais de $95 \%$, em especial as D), qualquer que seja a formação académica dos professores, sua situação e experiência profissionais [10]. As V e E são geralmente levadas a cabo por grupos de alunos. Exemplos correntes são, a ilustração experimental da lei de Lavoisier pelo professor (D) ou alunos (V) e diferentes processos de separação dos componentes de uma mistura $\mathrm{NaC} 1$ /areia (E), desde que o exemplo não seja familiar ao aluno. $\mathrm{Na}$ Tabela 1 apresentam-se possíveis dimensões do TE e seus atributos (indicação tendencial) para cada um dos três formatos. Na selecção de tais dimensões privilegiou-se o grau de envolvimento dos alunos no TE (i.e., lógica construtivista).

Os atributos de cada dimensão na Tabela 1 representam, naturalmente, posições limite. Assim, são previsíveis situações de ensino em que, por exemplo, a iniciativa do planeamento seja negociada entre o professor e o aluno embora se proponha no essencial dever centrar-se neste último. Do mesmo modo, aquilo que pode parecer uma tarefa aberta pode não o ser se o professor só aceitar uma solução. Isto é, uma tarefa aberta não é só aquela que tem mais do que uma solução possível (usualmente centrada nos processos mais do que sobre os conteúdos) mas depende também se e do modo como, o professor aceita as diferentes soluções propostas pelo aluno.

\footnotetext{
aniversidade de Aveiro.
} 
TABELA 1

Atributos correspondentes às dimensões e formatos do TE

\begin{tabular}{|l|c|c|c|}
\hline \multicolumn{1}{|c|}{ Formatos } & D & V & E \\
\hline Dimensōes & fechada & fechada & aberta \\
\hline 1 - Grau de abertura & P & P & A \\
\hline $2-$ Iniciativa do planeamento & P & A & A \\
\hline $3-$ Execução & P & P & A \\
\hline $4-\begin{array}{l}\text { Princípio de análise de dados exploração } \\
\text { sua }\end{array}$ & P-A & A-A & A-A \\
\hline $5-$ Interacções &
\end{tabular}

P: professor A: aluno

\section{(i) Dimensões 1, 2 e 4}

Se a intenção é aproximar a realização do TE do tipo de situações problema encontradas na investigação científica, as tarefas abertas são usualmente reconhecidas como mais vantajosas [11]. Pelo mesmo motivo, a iniciativa do planeamento e princípio da análise de dados (Dimensões 2 e 4) devem estar centradas nos alunos de modo a dar-lhes a oportunidade de p.ex.: tentar definir operacionalmente variáveis e sugerir modos de as controlar. Estudos de casos recentemente descritos envolvendo alunos Portugueses parecem adaptados a estas duas dimensões [12]. De acordo com a Tabela 1 resulta que o formato de TE que melhor se adapta às dimensões 1,2 e 4 são as Explorações. Neste caso, o ênfase do TE não é pois a mera ilustração dos conteúdos (caso das D nomeadamente) mas sim um compromisso entre conteúdos e processos.

\section{(ii) Dimensões 3 e 5}

Se o objectivo do professor é promover o desenvolvimento de habilidades manipulativas, o formato mais adequado é, Verificações ou Explorações. De notar que a execução experimental pelos alunos pode ainda servir dois importantes fins:

a) Apreciar a Química como ciência experimental (cheiros, frustração de uma experiência mal sucedida...).

b) Permitir-lhes melhor gerir o seu ritmo de aprendizagem já que o ritmo da informação passou agora a poder ser também controlado pelo aluno e não apenas pelo professor.

Finalmente, interacções verbais (dimensão 5) do tipo aluno-aluno (mais frequentes em princípio quando estes trabalham em grupo) favorecem a função ideacional da linguagem [13] e por isso mesmo a construção do conhecimento, já que permitem aos alunos um maior grau de especulação, espontaneidade e problematização das situações. Também aqui o formato de TE melhor adaptado é, Verificações ou Explorações.

A ausência das Demonstrações na discussão anterior nem por isso significa que não haja razões para as usar (ver Tabela 2). De notar que a lógica de construção da Tabela 2 tem agora a ver com aspectos relativos à organização do ensino na sala de aula.
TABELA 2

Vantagem relativa das condições de realização dos diferentes formatos de TE

\begin{tabular}{|l|c|c|c|}
\hline \multicolumn{1}{|c|}{ Formato } & D & V & E \\
\hline Condições & + & - & - \\
\hline $\begin{array}{l}\text { Recursos disponíveis } \\
\text { (instalações/equipamento) }\end{array}$ & + & - & - \\
\hline Segurança & + & - & - \\
\hline Tempo & & & - \\
\hline
\end{tabular}

+1-: maior/menor vantagem relativa.

A análise das Tabelas 1 e 2 sugere duas conclusões:

1 - A escolha do formato de TE cujo uso é actualmente privilegiado nas aulas de Química, as Demonstrações [10], só se justifica por factores ligados à organização e gestão do ensino na sala de aula e não por aspectos centrados na aprendizagem dos alunos. Não é pois de admirar a existência de falsas expectativas nos professores no que respeita ao papel desempenhado pelo TE na aprendizagem da Química.

2 - Nenhum dos formatos de TE apresentados encerra em $\mathrm{si}$ as virtualidades suficientes que o façam preferir de um modo absoluto a qualquer outro. Tal significa que os professores devem estar preparados para usar diferentes opções de TE. A escolha do formato mais adequado deve ser feita de acordo com os seus próprios objectivos e condições de trabalho. As Tabelas 1 e 2, como matrizes de decisão que são, poderão eventualmente ajudar a tomar opções mais criteriosas.

\section{Conclusões}

A sistematização feita sobre aspectos da problemática do TE teve como objectivo central facilitar aos professores de Química a reflexão sobre as suas práticas de ensino. Numa $1{ }^{a}$ fase, tal reflexão passa pela(s) resposta(s) a três questões:

(i) o que pretendo eu com uma dada experiência?

(ii) que formato de TE é o mais adequado (ver Tabelas $1 \mathrm{e}$ 2) para esse fim?

(iii) não haverá outros métodos mais vantajosos para atingir esses mesmos objectivos?

A resposta satisfatória a estas questões nem por isso significa que o TE se realize com sucesso. Em particular, a implementação do TE sofre frequentemente de falta de contexto, uma vez que os alunos não sabem muitas vezes porque é que estão realizando uma dada experiência. É pois importante que se lhes esclareça quais os fins da experiência que vão realizar, os procedimentos experimentais a adop$\operatorname{tar}($ caso de V) e a articulação entre uns e outros [14]. Um dos lugares privilegiados para iniciar a reflexão cuidada sobre o sentido a dar ao TE em Química é no contexto da formação inicial e em serviço dos professores de Química. Tal reflexão deve basear-se em investigação educacional, se possível participada pelos professores em formação. O papel do Boletim da Sociedade Portuguesa de Química na difusão dos frutos de tal reflexão será no meu entender insubstituível. 


\section{Referências}

[1] WOOLNOUGH, B.E. (1983), «Towards a rationale for practical work in school science: implications for training teachers». In Tamir, P., Hofstein, A. and Ben-Peretz, M., (Ed.), Proceedings of the Internacional Seminar «Preservice and Inservice Education of Science Teachers», University of Jerusalem, p. 415-421

[2] GARRETT, R.M. and ROBERTS, I.F. (1982). «Demonstration versus small group pratical work in science education. A critical review of studies since 1900m. Studies in Science Education, n. ${ }^{\circ} 9$

[3] SOLOMON, J. (1980). "Teaching children in the laboratory». Croom Helm

[4] HOFSTEIN, A. and LUNETTA, V, (1982). «The role of the laboratory in science teaching: neglected aspects of research». Review of Educational Research, 52(2), p. 201-207

[5] OSBORNE, R. and WITTROCK, M. (1985). «The generative learning model and its implications for science education». Studies Sci. Educ., 12 , p. $59-87$

[6] KUBLI, F. (1979). «Piaget's cognitive psychology and its consequence for the teaching of science». Eur, Journal of Science Education, 1(1), p. 5-20

[7] KYLE, W.C. (1980). «The distinction between inquiry and scientific inquiry and why high school students should be cognizant of the dis- tiction». J. Res. Sci. Teaching, 17, p. 123-130

[8] DRIVER, R. (1975). «The name of the game». S.S.R., 56 (197), p. $800-805$

[9] WELLINGTON, J. (1981). «What's supposed to happen sir?». S.S.R., 63 (222), p. 167-173

[10] CACHAPUZ, A., MALAQUIAS, I., MARTINS, I., THOMAZ, M. e VASCONCELOS, N., (Grupo INEA/FQ). \&O trabalho experimental nas aulas de Física e Química: uma perspectiva nacional». Trabalho de investigação submetido para publicação na Gazeta de Física, em 1988 [11] PAVELICH, M. and ABRAHAM, M. (1979). "An Inquiry format laboratory program for general chemistry», J. Chem. Educ., 56, (2), p. 100-103

[12] CACHAPUZ, A., ROCHA, J. e JESUS, H. «Química e Ambiente: como de um problema ambiental se construiu uma estratégia de ensino do conceito de reacção química - ensino básico». Trabalho de investigação submetido para publicação no Boletim da Sociedade Portuguesa de Química, em 1989

[13] The Association for Science Education (1980). «Language in Science». College Lane, Hatfield, Herts, England

[14] GALLAGHER, J. and TOBIN, K. (1987). «Teacher management and student engagement in high school sciences. Science Education, 71(4), p. $535-555$

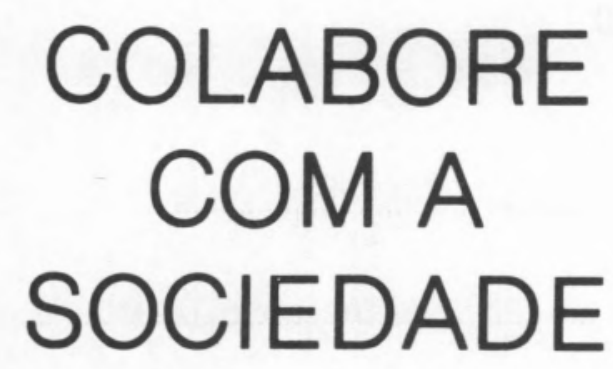

\section{NÃO ATRASE O PAGAMENTO DAS SUAS QUOTAS}




\section{ENCONTRO COMPUTADORES NO ENSINO DA FÍSICA E DA QUÍMICA}

A Sociedade Portuguesa de Física, a Sociedade Portuguesa de Química e o Projecto Minerva organizam um encontro sobre Computadores no Ensino da Física e da Química, na Universidade de Coimbra, de 22 a 24 de Fevereiro de 1990.

\section{OBJECTIVOS:}

- Reunir...

- Divulgar...

- Discutir...

Os interessados devem enviar uma pré-inscrição até ao dia 30 de Julho próximo para: Departamento de Física da Universidade de Coimbra, 3000 COIMBRA.

\section{Ficha de pré-inscrição}

COMPUTADORES NO ENSINO DA FÍSICA E DA QUÍMICA

Departamento de Física da Universidade de Coimbra, 3000 COIMBRA

22-24 Fevereiro de 1990

Nome

Morada

Telefone

Escola

Sócio SPF

Sócio SPQ

Delegado Projecto Minerva

Tenciona apresentar uma comunicação? 